\title{
The challenge of discovering beneficial viruses
}

The most important effect of viruses on the human body is to cause infectious diseases. A number of serious diseases in humans are the result of viral infection, including influenza, haemorrhagic fever, severe acute respiratory syndrome (SARS) and acquired immunodeficiency syndrome (AIDS). Deaths from infectious viral diseases make up a large proportion of those worldwide from human disease. Some viruses are recognized in the aetiology of non-infectious conditions, including inflammation, cancers and other life-threatening diseases. Even though many recent studies on new antiviral approaches focused on vaccines and RNA interference technology, and have obtained promising outcomes, newly identified human viruses, such as Ebola virus (Bermejo et al., 2006), SARS-CoV (Tsang et al., 2003), Nipah virus (Bellini et al., 2005) and H5N1 highly pathogenic avian influenza virus (Oner et al., 2006), are continually found. These create serious challenges to worldwide public health. Therefore, new strategies are needed to counteract pathogenic viruses.

As well as negative roles, micro-organisms also have beneficial functions. The biological world is harmonious. Many different micro-organisms coexist in an overall symbiotic relationship, such as the complex array of commensal bacterial flora that colonizes the gastrointestinal tract. Some symbiotic bacteria are beneficial to the human body (Sekirov \& Finlay, 2006), and play an important role in the decomposition and absorption of food and other substances, including medicines. Quite simply, in the case of human dysbacteriosis, the alteration of the flora will result in diarrhoea and other intestinal disorders. As another example, many parasitoid wasps species are known to harbour symbiotic viruses, and these viruses have a mutual relationship with their wasp host, particularly for host immune responses (Renault et al., 2005). This poses the question: are there beneficial symbiotic viruses in the human body which protect humans from infections caused by other viruses?

It has been shown that many primary viral infections prevent superinfection caused by a homologous secondary virus.

Interference between viruses occurs when infection by one virus results in the inhibition of replication of another virus. For example, hepatitis A virus infection suppresses hepatitis $\mathrm{C}$ virus replication, and may lead to recovery from hepatitis $\mathrm{C}$ virus (Deterding et al., 2006). Prior infection with human cytomegalovirus impeded subsequent superinfection with human immunodeficiency virus (HIV); in contrast, uninfected bystander cells within the population were still permissive for HIV infection (King et al., 2006). The nature of these phenomena is unclear at present, but increasing findings support the hypothesis that interference of virus infection may involve multiple mechanisms, including STAT activation (Bovolenta et al., 2002), intermolecular competition for the formation of active chromatin structure, virus gene mutation (Jardi et al., 2001), transcriptional regulation (Flichman et al., 1999), induction of antiviral cytokines or cellular resistance to another virus (van Nunen et al., 2001), and interference or downmodulation of cellular receptors for viruses (Crowley et al., 1996).

The interference of homologous and heterologous viruses has been well studied in vitro. However, most of the currently identified human viruses were isolated from patients, and all interfering viruses known today are pathogenic for humans. Virus isolation focuses on pathogenic viruses rather than possible beneficial viruses. The beneficial or symbiotic viruses that may be non-pathogenic microorganisms in humans should never be ignored!

Some people may not be ill, even if they are infected with or exposed to a pathogenic virus. As examples, we see long-term nonprogressors with HIV infection, individuals with long-term highrisk exposure to HIV, populations with low morbidity of virus-related cancers, and individuals who remain free of illness in epidemics or pandemics of serious viral diseases. To explore these interesting phenomena, most current studies only look at the viral genome, genetic susceptibility and immunity; few associate these cases with the possibility of beneficial viruses. In fact, many genetic variations exist in both 'healthy' people and patients; and genetic diversity varies as well as severity of disease. Traditional laboratory techniques, such as the use of certain cell strains and culture conditions, may affect the results of virus isolation. The inability to cultivate most host-associated microbes hampers our understanding of beneficial viruses, which in turn limits the awareness of the possible existence of such viruses.

However, in support of the concept of beneficial viruses, a recent study (Venkataraman et al., 2008) revealed that 'Seneca Valley Virus-001' demonstrates cancer-killing specificity that is 10000 times higher than that seen in traditional chemotherapeutics, with no overt toxicity; and that the $3 \mathrm{D}$-structure of the virus is unlike that of any other known member of the virus family Picornaviridae. Thereby, it is reasonable to speculate that beneficial viruses may already exist, and what we need to do is to find out what they are and what their role is. Isolating beneficial viruses is a considerable challenge, and the critically important first step is to find out what region of its structure the virus is using to bind to target cells, and what those target cell receptors are. Then the beneficial virus may be used for treatment of disease.

To uncover beneficial viruses will be certainly a great project, and requires more attention from biological scientists all over the world. It will, however, be a great revolution in the field of biology if beneficial viruses become potent agents 
that can be used as therapy for many

different diseases.

\section{Hong-Hui Shen}

Institute of Infectious Diseases, Beijing 302 Hospital, Beijing, PR China

Correspondence: Hong-Hui Shen (shenhh@yahoo.cn)

Bellini, W. J., Harcourt, B. H., Bowden, N. \& Rota, P. A. (2005). Nipah virus: an emergent paramyxovirus causing severe encephalitis in humans. J Neurovirol 11, 481-487.

Bermejo, M., Rodriguez-Teijeiro, J. D., Illera, G., Barroso, A., Vila, C. \& Walsh, P. D. (2006). Ebola outbreak killed 5000 gorillas. Science 314, 1564.

Bovolenta, C., Pilotti, E., Mauri, M., Panzeri, B., Sassi, M., Dall'Aglio, P., Bertazzoni, U., Poli, G. \& Casoli, C. J. (2002). Retroviral interference on STAT activation in individuals coinfected with human T cell leukemia virus type 2 and HIV-1. J Immunol 169, 4443-4449.
Crowley, R. W., Secchiero, P., Zella, D., Cara, A., Gallo, R. C. \& Lusso, P. (1996). Interference between human herpesvirus 7 and HIV-1 in mononuclear phagocytes. J Immunol 156, 2004-2008.

Deterding, K., Tegtmeyer, B., Cornberg, M., Hadem, J., Potthoff, A., Boker, K. H., Tillmann, H. L., Manns, M. P. \& Wedemeyer, H. (2006). Hepatitis A virus infection suppresses hepatitis $\mathrm{C}$ virus replication and may lead to clearance of HCV. J Hepatol 45, 770-778.

Flichman, D., Cello, J., Castano, G., Campos, R. \& Sookoian, S. (1999). In vivo down regulation of HIV replication after hepatitis C superinfection. Medicina (B Aires) 59, 364-366.

Jardi, R., Rodriguez, F., Buti, M., Costa, X., Cotrina, M., Galimany, R., Esteban, R. \&

Guardia, J. (2001). Role of hepatitis B, C, and D viruses in dual and triple infection: influence of viral genotypes and hepatitis $B$ precore and basal core promoter mutations on viral replicative interference. Hepatology 34, 404-410.

King, C. A., Baillie, J. \& Sinclair, J. H. (2006). Human cytomegalovirus modulation of CCR5 expression on myeloid cells affects susceptibility to human immunodeficiency virus type 1 infection. J Gen Virol 87, 2171-2180.
Oner, A. F., Bay, A., Arslan, S., Akdeniz, H. Sahin, H. A., Cesur, Y., Epcacan, S., Yilmaz, Z., Deger, I. \& other authors (2006). Avian influenza A (H5N1) infection in eastern Turkey in 2006. N Engl J Med 355, 2179-2185.

Renault, S., Stasiak, K., Federici, B. \& Bigot, Y. (2005). Commensal and mutualistic relationships of reoviruses with their parasitoid wasp hosts. J Insect Physiol 51, 137-148.

Sekirov, I. \& Finlay, B. B. (2006). Human and microbe: united we stand. Nat Med 12, 736-737.

Tsang, K. W., Ho, P. L., Ooi, G. C., Yee, W. K., Wang, T., Chan-Yeung, M., Lam, W. K., Set, W. H., Yam, L. Y. \& other authors (2003). A cluster of cases of severe acute respiratory syndrome in Hong Kong. N Engl J Med 348, 1977-1985.

van Nunen, A. B., Pontesilli, O., Uytdehaag, F., Osterhaus, A. D. \& de Man, R. A. (2001).

Suppression of hepatitis B virus replication mediated by hepatitis A-induced cytokine production. Liver 21, 45-49.

Venkataraman, S., Reddy, S. P., Loo, J., Idamakanti, N., Hallenbeck, P. L. \& Redd, V. P. (2008). Structure of Seneca Valley Virus-001: an oncolytic picornavirus representing a new genus. Structure 16, 1555-1561. 